\title{
Readability of advance directive documentation in Canada: a cross-sectional study
}

\author{
Alby Richard PhD MD, Joël Richard MSc BEd, Wendy Johnston MD, Janis Miyasaki MD MEd
}

\section{Abstract}

Background: In the Canadian context, health literacy has been shown to depend on place of birth, education level, socioeconomic status, language spoken and geographic location. This study seeks to determine whether currently available advance directive documentation in Canada is written in accordance with the average reading level of the population and to assess whether recommendations for health literacy are currently being met.

Methods: A cross-sectional study design was used. Patient-oriented English-language advance directive documents (brochures and/ or forms) were obtained from the health agency websites of all Canadian provinces and territories and analyzed for readability using the Flesch-Kincaid Grade Level and Flesch Readability Ease scales.

Results: Advance directives in Canada are distinct from one another and surpass the recommended reading level by $4.5 \pm 1.4$ grade levels on average (95\% confidence interval 8.7-10.3) with the hardest-to-read documents existing in Ontario, Quebec and Alberta.

Interpretation: These results demonstrate that the provincial and territorial governments issuing advance directive documentation have fallen short of their fiduciary responsibility to provide documents that facilitate health literacy. Addressing this shortcoming can result in increased patient engagement in advance directive completion while promoting patient autonomy.

1 o make appropriate health decisions, people must be able to articulate their individual preferences for the health care interventions they receive. This ability is generally referred to as health literacy, which broadly refers to the degree to which an individual has the capacity to process, understand and communicate basic health information. ${ }^{1}$ An important role for health care professionals in this context is to assist patients in accessing readily understandable health policy documentation. This not only contributes to health literacy but also facilitates patient autonomy to ensure the best possible health outcomes.

In the absence of available advance directive documentation, the goals of care for an individual are generally determined by the medical provider (i.e., physicians and primary care providers) according to recognized statutes of reasonable care. Owing in part to the discrepancies between provincial and territorial jurisdictions around such documentation, it is not currently known how many Canadians have made their wishes explicit in a legally recognized form. ${ }^{2}$ What is clear, however, is that without any such documentation the chances of a meaningful dialogue between a vulnerable individual and the health care system decrease significantly. As such, advance directive documents are important tools that inform and frame health literacy by establishing the groundwork for individuals and care providers to comprehend one another.

In Canada, health literacy depends on a number factors including place of birth, education level, socioeconomic status, language spoken (English v. French) and geographic location. ${ }^{1}$ Low health literacy is associated with fewer health-promoting behaviours, poorer health status, higher rates of hospital admission and higher health care costs. ${ }^{3}$ Moreover, people who rate their health as fair or poor have the lowest levels of language proficiency and general health literacy. ${ }^{4}$ Among the most crucial times for comprehension of medical information and assurance of patient autonomy is the time of completion of an advance directive. This process is meant to document individuals' wishes in the event that they are not able to speak for themselves. Currently there is no federally prescribed advance directive documentation

\section{Competing interests: None declared.}

This article has been peer reviewed.

Correspondence to: Alby Richard, arichar8@bidmc.harvard.edu CMAJ Open 2018. DOI:10.9778/cmajo.20180037 
available in Canada; most advance directive documentation is provided by individual provinces or territories. Individuals also have the option of using an institutional template or drafting their own form.

Canada's demographic profile is shifting (by 2056, 25\% to $30 \%$ of Canada's population will be older than 65 years of age), and it has been estimated that within the next few decades, more than $75 \%$ of Canadians will have at least 1 chronic condition. ${ }^{5}$ These trends portend a significant increase in demand for health services, ${ }^{6}$ while underscoring the importance of addressing barriers that may prevent individuals from expressing their medical wishes in a timely and unambiguous manner. Importantly, many of the same factors that influence health literacy also affect the completion of an advance directive. Pertinent among these is education level, ${ }^{7}$ with the highest rates of advance directive completion seen in those who have completed high school. ${ }^{8}$ The average reading level in Canada and the United States is in the range of 8 th grade or lower. ${ }^{9,10}$ It is therefore not surprising that many studies demonstrate that patient materials (including informed consent forms, educational materials and advance directive forms) are virtually incomprehensible to most adults. ${ }^{11,12}$ The Canadian Council on Learning has reported that " $60 \%$ of adults in Canada lack the capacity to obtain, understand and act upon health information and services and to make appropriate health decisions on their own."13 This mirrors the situation in the US, where a large proportion of health information materials are written at a level that exceeds the reading skills of the average high school graduate. ${ }^{14} \mathrm{~A}$ recent analysis of governmentsponsored advance directive documentation in the US showed an alarming discrepancy between the readability of these documents and the average literacy level of adults, prompting the National Work Group on Literacy and Health to recommend that health care documentation be written at a 5 th grade reading level. ${ }^{10}$ Our objective in this report was to assess the readability of English-language government-sponsored advance directive documentation available in Canada while highlighting its role in promoting health literacy and increased patient autonomy.

\section{Methods}

\section{Document selection}

We accessed English-language advance directive documents for every Canadian province and territory from the websites of their respective government health agencies and analyzed their readability and content. Forms in French and/or Indigenous languages could not be located for every province and territory and were thus excluded from subsequent analysis. In some cases, advance directive documents were collected by querying the Google search engine with the following keywords: "advance directive," "DNR" [do not rescuscitate] and/or "personal directive," along with the name of the province or territory. All of the government websites accessed for this study were validated by critical inspection by one of the coauthors to ensure that the Web address and content matched and that the documents from each website matched their cognate jurisdiction. No authentication tool was used. Although the websites of some jurisdictions provided more than 1 option, only commonly used advance directive documents were selected for further inquiry. We also ensured that, where possible, we selected for analysis advance directive documents targeted to patients and their families (and not, for example, oriented toward health care providers).

\section{Readability analysis}

All of the advance directive forms used in this study were accessed on Feb. 20, 2018, and recovered as portable document format (PDF) files. These were converted to Microsoft Word (.doc) format using a file converter software package (Adobe Acrobat 9 Pro version 9.5.5) and visually inspected to ensure that the conversions were accurate and complete. Any forms with embedded French-language sections were edited to remove these sections before subsequent analysis. All of the .doc formatted advance directive documents were then subjected to readability analysis using Microsoft Word for Mac 2011 software (version 14.7.2) to derive their Flesch-Kincaid Grade Level and Flesch Reading Ease scores. This method was chosen because it is commonly used to assess the readability of written materials, and it correlates well with other readability metrics previously used to assess health care materials. ${ }^{10,15}$ The Flesch-Kincaid Grade Level score provides a best approximation of the equivalent grade reading level (between 0 and 19) for the analyzed text, whereas the Flesch Reading Ease score provides a numerical value (between 0 and 100), with a low score indicating that a document is difficult to read. While the Flesch-Kincaid Grade Level metric for readability was not originally conceived for use in health care settings, it remains a validated and accepted tool that is used ubiquitously in the health care literature. ${ }^{15}$ Moreover, the results of the Flesch-Kincaid correlate very well with other metrics of readability (e.g., Automated Readability Index, Simplified Automated Readability Index) when compared head to head. ${ }^{10}$

\section{Statistical analysis}

One-sample non-parametric Wilcoxon tests (comparison values of 8 and 5 used for the average grade readability and recommended reading level, respectively) were used to compare the mean Canadian Flesch-Kincaid Grade Level scores with the average and recommended reading level in the US. All statistical analyses were performed in MATLAB (MathWorks), using the Statistics Toolbox.

\section{Comparative document analysis}

As part of this cross-sectional study, various qualitative metrics (format, publication date, page count and word count) were sought to describe each of the advance directive documents analyzed in this study. The year of publication for each document was taken either directly from the PDF itself or from the publication date affiliated with the Web link used to access the document. Furthermore, to describe each 
document's specific content, a single coauthor examined the set of documents used for this study to delineate whether they contained: (a) clinical language suitable for a specialized audience, (b) open-ended fields that solicit direct patient input, (c) a "do not resuscitate" proviso, (d) a postmortem tissue donation proviso, (e) a glossary of terms for important definitions and (f) a prep sheet with precise instructions on how to complete the form.

\section{Ethics approval}

Ethics approval was not required for this study because the data were accessed from a publicly available source of information that was legally accessible to the public and protected by law, in accordance with the Tri-Council Policy Statement: Ethical Conduct for Research Involving Humans (TCPS2). ${ }^{16}$

\section{Results}

English-language advance directive documents were collected for each Canadian province and territory and subjected to readability analysis to derive their Flesch-Kincaid Grade Level and Flesch Reading Ease scores, metrics that are widely used with proven reliability. ${ }^{10}$ In total, 13 documents were analyzed, 1 for each of the provinces and territories in Canada. The Grade Level scores for all provincial and territorial forms are displayed in Figure 1; only 2 (the scores for the forms from Saskatchewan and New Brunswick) were below the average reading level of adults in the US. The average readability score of advance directive documentation in Canada was significantly higher $(4.5 \pm 1.4$ grade levels, $95 \%$ confidence interval 8.7-10.3) than the US recommended grade

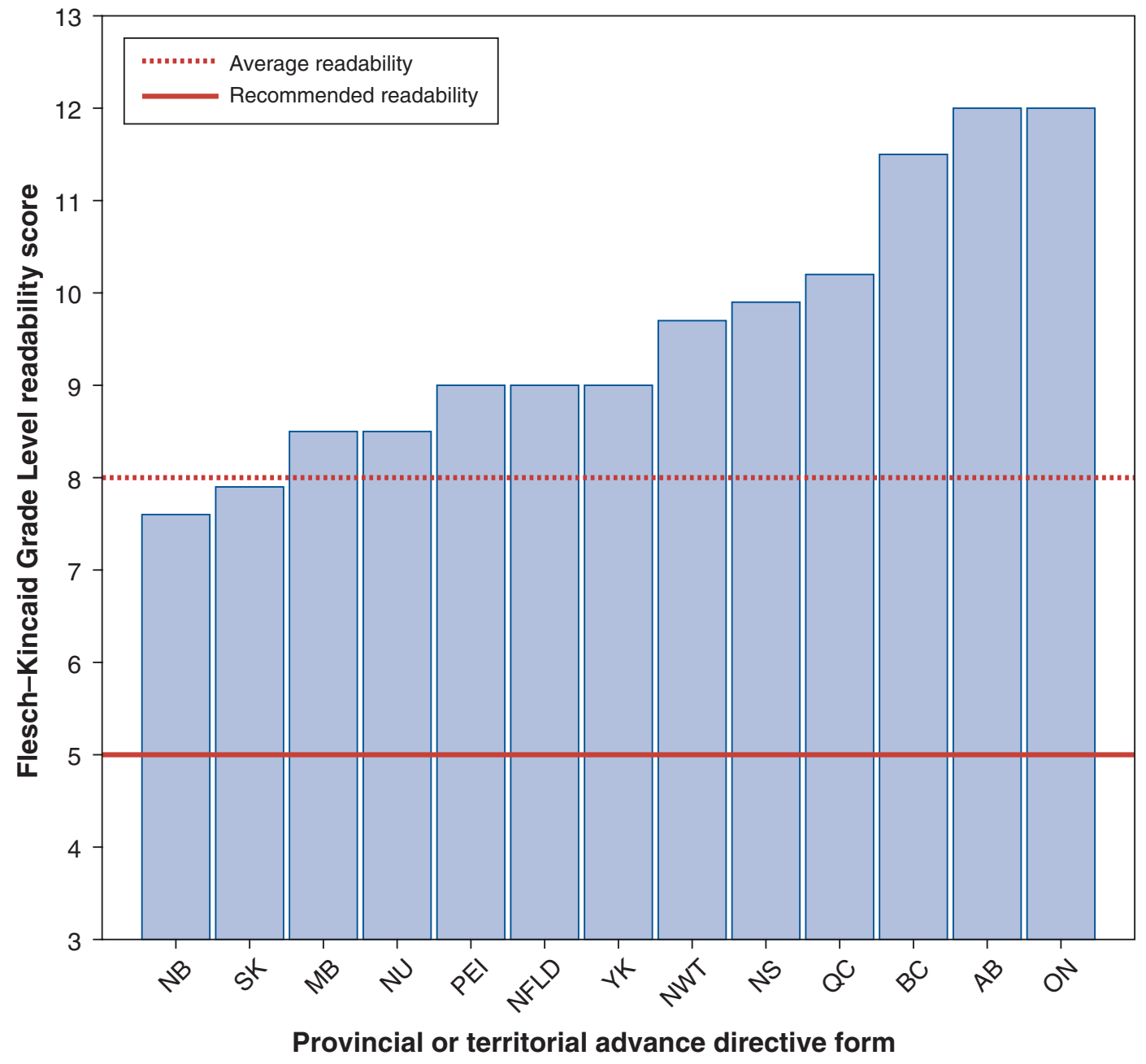

Figure 1: Flesch-Kincaid Grade Level readability scores for the advance directive forms of the 13 provinces and territories of Canada. Each bar represents grade level readability. Highlighted are the average readability level (8th grade, red hatched line) and recommended readability levels for health documentation (5th grade, red solid line). Note: $A B=$ Alberta, $B C=$ British Columbia, $M B=$ Manitoba, NB = New Brunswick, NFLD = Newfoundland, NS = Nova Scotia, NWT = Northwest Territories, NU = Nunavut, ON = Ontario, PEI = Prince Edward Island, QC = Quebec, SK = Saskatchewan, $\mathrm{YK}=$ Yukon. 
level (Table 1). We compared our results with those from US advance directive documents because the populations of the 2 countries are comparable in terms of their basic reading level..$^{13,14}$

To further contextualize the readability scores we obtained, we assessed each of the advance directive documents in our study in terms of its formatting and content. Table 2 presents our comparative document analysis, which highlights the disparate nature of advance directive documents across Canada. Some health jurisdictions (e.g., Manitoba) rely on simple, open-ended templates meant to be completed and retained by the patients themselves, whereas others (e.g., British Columbia) employ a hybrid format with space for input from patients mixed with jargon-heavy sections whose completion is meant to be overseen by a legal or health care professional. In 1 case (Quebec), advance directive forms are administered through a secure Internet portal in order to be tracked electronically by the provincial health agency and made freely accessible to the province's doctors. Documents from the Northwest Territories and Nunavut were excluded from the content analysis in Table 2 because their format (i.e., as a government-sponsored webpage and Territorial Legal Act, respectively) could not be validly compared with the rest.

\section{Interpretation}

The present report demonstrates that English-language advance directive documentation in Canada exceeds the readability level recommended by the US National Work Group on Literacy and Health, as well as the average reading skill of adults in both the US and Canada. ${ }^{3,13,14}$ We have demonstrated that the readability of advance directive documents available in Canada surpasses the recommended reading level by 4.5 grade levels on average, with Ontario, Quebec and Alberta having the hardest-to-read documents.

These results are concerning because illegible advance directive documentation represents a significant obstacle to both health literacy and patient autonomy. Health care in Canada is provincially/territorially adjudicated, where regional health care authorities are responsible for the provision of information regarding health care decisions. On the basis of the results presented here, it is clear that most, if not all, provincial/territorial health agencies in Canada are currently failing to meet their fiduciary responsibility of providing clear and concise advance directive documents for their citizens. This problem is tractable, however, and the provision of language-adjusted documentation (i.e., a reading level either equivalent to or below the average reading level of the population) would contribute to increased engagement in the advance directive process while also promoting health literacy and patient autonomy.

There is no universally recognized template for the production of clear and concise advance directive documentation, and the documents investigated in this study each possessed strengths and weaknesses. As demonstrated, there is a clear lack of standardization across Canada in terms of the language and practices used to design and implement these crucial documents. This disharmony is an impediment for both patients and health care providers when it comes to endof-life planning ${ }^{2}$ and highlights an important area of concern as our aging population is increasingly confronted with these questions. Our results suggest that improving Canadian advance directive documents will entail more than simply adjusting their language to reduce their readability scores. Document variables (e.g., length, comprehensiveness, layout and/or cultural appropriateness), in addition to other factors such as patient age or personal/medical history, could also affect patient engagement and form completion rates. ${ }^{17}$ Understanding these elements could also lead to efforts to increase the legibility of this documentation, and ultimately, to improved patient engagement. Moreover, from the health care provision perspective, more effective and efficient advance directive documentation can also facilitate communication between patients and health care providers while contributing to more holistic care.

\section{Limitations}

This study had important limitations, one of which was the failure to address the readability of advance directive forms in languages other than English. Forms written in French, Indigenous languages or other commonly spoken languages were not evaluated. Another possible limitation is the exclusive use of the Flesch-Kincaid Grade Level and Flesch Reading Ease tools for all quantitative document analysis. This scale is available only in English, and while it is a well-established and validated tool, it was not initially devised for material that relates to health care or health literacy. Moreover, the use of formulaic readability algorithms such as the Flesch-Kincaid Grade Level and Flesch Reading Ease tools has the inherent flaw of not determining whether written materials are comprehensible or not. For example, it is not always the case that sentence length correlates directly with readability (as it does in most formulae like the Flesch-Kincaid Grade Level and Flesch Reading Ease scales). Shorter sentences with outdated or seldom used vocabulary may be more difficult to understand than longer sentences written with simpler words. Finally, the analysis presented here did not take the formatting of the various advance directive forms into account (e.g., font size and spacing, colour schemes, graphics and illustrations), which could affect overall readability. One way to approach this problem would be to conduct focus groups and solicit direct patient feedback on which formats are easiest to read and complete.

\section{Conclusion}

Provincial and territorial health agencies oversee the distribution of advance directive documentation, and our results demonstrate the different approaches used to create and administer advance directives in terms of authorship, publication year, length, density of information and intended audience. Taken together, the readability and comparative document analysis presented here support the observation that there are significant differences among the English language advance directive documents commonly used in Canada. Moving forward, 


\begin{tabular}{|c|c|c|c|c|c|}
\hline Scale & Median (range) & Mean \pm SD & IQR & $95 \% \mathrm{Cl}$ & WS \\
\hline $\begin{array}{l}\text { Flesch-Kincaid Grade } \\
\text { Level }\end{array}$ & $9.00(7.60-12.00)$ & $9.60 \pm 1.47$ & 2.03 & $8.75-10.61$ & $\begin{array}{l}88^{*} \\
91 \dagger\end{array}$ \\
\hline Flesch Reading Ease & $54.80(22.10-72.00)$ & $51.44 \pm 14.76$ & 14.83 & - & - \\
\hline \multicolumn{6}{|c|}{$\begin{array}{l}\text { Note: } \mathrm{CI}=\text { confidence interval, IQR }=\text { interquartile range, } \mathrm{SD}=\text { standard deviation, } \mathrm{WS}=\text { Wilcoxon statistic. } \\
\text { "Value compared with average readability grade level (i.e., 8th grade). } \\
\text { †Value compared with recommended readability level (i.e., } 5 \text { th grade). }\end{array}$} \\
\hline
\end{tabular}

\begin{tabular}{|c|c|c|c|c|c|c|c|c|c|c|}
\hline Province or territory, URL & Format & Date & $\begin{array}{l}\text { No. of } \\
\text { pages }\end{array}$ & $\begin{array}{l}\text { No. of } \\
\text { words }\end{array}$ & $\begin{array}{l}\text { Clinical } \\
\text { language }\end{array}$ & $\begin{array}{l}\text { Open- } \\
\text { ended } \\
\text { fields }\end{array}$ & $\begin{array}{l}\text { Do-not- } \\
\text { resuscitate } \\
\text { option }\end{array}$ & $\begin{array}{l}\text { Tissue } \\
\text { donation } \\
\text { option }\end{array}$ & $\begin{array}{l}\text { Glossary } \\
\text { of terms }\end{array}$ & $\begin{array}{l}\text { Prep } \\
\text { sheet }\end{array}$ \\
\hline $\begin{array}{l}\text { British Columbia, } \\
\text { www.health.gov.bc.ca/library/ } \\
\text { publications/year/2013/ } \\
\text { MyVoice-AdvanceCarePlanningGuide. } \\
\text { pdf }\end{array}$ & $\begin{array}{l}\text { Brochure/ } \\
\text { form }\end{array}$ & 2013 & 56 & 6316 & & $\checkmark$ & & & $\checkmark$ & $\checkmark$ \\
\hline $\begin{array}{l}\text { Alberta, } \\
\text { www.albertahealthservices.ca/ } \\
\text { frm-103547.pdf }\end{array}$ & Form & 2014 & 2 & 1286 & $\checkmark$ & $\checkmark$ & $\checkmark$ & & $\checkmark$ & \\
\hline $\begin{array}{l}\text { Saskatchewan, } \\
\text { www.rqhealth.ca/rqhr-central/files/ } \\
\text { ceac_1042.pdf }\end{array}$ & $\begin{array}{c}\text { Brochure/ } \\
\text { form }\end{array}$ & 2014 & 29 & 6602 & & $\checkmark$ & $\checkmark$ & $\checkmark$ & $\checkmark$ & $\checkmark$ \\
\hline $\begin{array}{l}\text { Manitoba, } \\
\text { www.gov.mb.ca/health/documents/hcd. } \\
\text { pdf }\end{array}$ & Form & 2004 & 2 & 875 & & $\checkmark$ & & & & \\
\hline $\begin{array}{l}\text { Ontario, } \\
\text { www.forms.ssb.gov.on.ca/mbs/ssb/ } \\
\text { forms/ssbforms.nsf/GetFileAttach/ } \\
\text { 014-4519-45 1/\$File/4519-45.pdf }\end{array}$ & Form & 2008 & 1 & 383 & $\checkmark$ & & $\checkmark$ & & & \\
\hline $\begin{array}{l}\text { Quebec, } \\
\text { www.ramq.gouv.qc.ca/en/citizens/ } \\
\text { Pages/advance-medical-directives } \\
\text {-download-the-form.aspx }\end{array}$ & Form & 2017 & 6 & 2561 & $\checkmark$ & & $\checkmark$ & & $\checkmark$ & $\checkmark$ \\
\hline $\begin{array}{l}\text { New Brunswick, } \\
\text { www2.gnb.ca/content/dam/gnb/ } \\
\text { Departments/h-s/pdf/en/Patients/ } \\
\text { Form-AdvanceHealthCareDirective.pdf }\end{array}$ & Form & 2016 & 3 & 342 & & $\checkmark$ & & & & \\
\hline $\begin{array}{l}\text { Nova Scotia, } \\
\text { http://novascotia.ca/just/pda/_docs/ } \\
\text { PersonalDirectiveLongForm0311.pdf }\end{array}$ & $\begin{array}{l}\text { Brochure/ } \\
\text { form }\end{array}$ & 2010 & 20 & 6108 & & $\checkmark$ & & & $\checkmark$ & $\checkmark$ \\
\hline $\begin{array}{l}\text { Prince Edward Island, } \\
\text { www.gov.pe.ca/forms/pdf/2797.pdf?_ga } \\
=1.14385655 .1761787984 .145624769 \\
2\end{array}$ & Form & 2016 & 8 & 1608 & & $\checkmark$ & & $\checkmark$ & & \\
\hline $\begin{array}{l}\text { Newfoundland and Labrador, } \\
\text { www.cssd.gov.nl.ca/publications/pdf/ } \\
\text { seniors/ahcd_booklet.pdf }\end{array}$ & $\begin{array}{l}\text { Brochure/ } \\
\text { form }\end{array}$ & 2017 & 10 & 2018 & & $\checkmark$ & & $\checkmark$ & & $\checkmark$ \\
\hline $\begin{array}{l}\text { Yukon, } \\
\text { www.hss.gov.yk.ca/pdf/adv_directive_ } \\
\text { booklet.pdf }\end{array}$ & Form & 2017 & 24 & 4305 & & $\checkmark$ & $\checkmark$ & & $\checkmark$ & $\checkmark$ \\
\hline $\begin{array}{l}\text { Northwest Territories, }{ }^{*} \\
\text { www.hss.gov.nt.ca/en/services/ } \\
\text { personal-directives }\end{array}$ & Website & 2017 & 2 & 724 & & & & & & \\
\hline $\begin{array}{l}\text { Nunavut, }^{*} \\
\text { www.gov.nu.ca/sites/default/files/ } \\
\text { Guardianship_\%26_Trusteeship_Act. } \\
\text { pdf }\end{array}$ & $\begin{array}{c}\text { Legal } \\
\text { document }\end{array}$ & 2015 & 42 & 13007 & & & & & & \\
\hline
\end{tabular}


we recommend that newly created advance directive documents be written and distributed on the basis of clearly articulated benchmarks that control for, among other things, the readability of the language they contain. Both health literacy and advance directive completion rates could be improved by standardizing these documents across Canada or perhaps even working toward producing a single advance directive form that could be used across the country.

\section{References}

1. Rootman I, Gordon-El-Bihbety D. A vision for a bealth literate Canada: report of the Expert Panel on Health Literacy. Ottawa: Canadian Public Health Association; 2008.

2. Vogel L. Advance directives: obstacles in preparing for the worst. CMAf 2011;183:E39-40.

3. Health literacy: a prescription to end confusion. Institute of Medicine (US) Committee on Health Literacy; Nielsen-Bohlman L, Panzer AM, Kindig DA, editors. Washington (DC): National Academies Press; 2004.

4. Murray MD, Young J, Hoke S, et al. Pharmacist intervention to improve medication adherence in heart failure: a randomized trial. Ann Intern Med 2007;146:714-25.

5. Schultz SE, Kopec JA. Impact of chronic conditions. Health Rep 2003;14:41-53.

6. Table: 13-10-0013-01 - Life expectancy, abridged life table, at birth and at age 65, by sex, Canada, provinces and territories (comparable indicators) [table]. Ottawa: Statistics Canada; (modified 2018 Aug. 22). Available: www150.statcan.gc.ca/t1/tbl1/en/tv.action?pid=1310001301 (accessed 2018 Feb. 10).

7. Hanson LC, Rodgman E. The use of living wills at the end of life: a national study. Arch Intern Med 1996;156:1018-22.

8. Nishimura A, Mueller PS, Evenson LK, et al. Patients who complete advance directives and what they prefer. Mayo Clin Proc 2007;82:1480-6.

9. Jamieson DG. Literacy in Canada. Paediatr Child Health 2006;11:573-4.
10. Mueller LA, Reid KI, Mueller PS. Readability of state-sponsored advance directive forms in the United States: a cross sectional study. BMC Med Ethics 2010;11:6.

11. Paasche-Orlow MK, Parker RM, Gazmararian JA, et al. The prevalence of limited health literacy. 7 Gen Intern Med 2005;20:175-84.

12. Paasche-Orlow MK, Taylor HA, Brancati FL. Readability standards for informed-consent forms as compared with actual readability. $N$ Engl $7 \mathrm{Med}$ 2003;348:721-6.

13. Health literacy in Canada: a bealthy understanding. Ottawa: Canadian Council on Learning; 2008.

14. Rudd R, Kirsch I, Yamamoto K. Literacy and health in America [policy information report]. Princeton (NJ): Educational Testing Service; 2004.

15. Badarudeen S, Sabharwal S. Assessing readability of patient education materials: current role in orthopaedics. Clin Orthop Relat Res 2010;468:2572-80.

16. Tri-Council policy statement: ethical conduct for research involving humans. Ottawa: Secretariat on Responsible Conduct of Research; 2014. Available: www. pre.ethics.gc.ca/pdf/eng/tcps2-2014/TCPS_2_FINAL_Web.pdf (accessed 2018 Sept. 14).

17. Wilson DM, Houttekier D, Kunju SA, et al. A population-based study on advance directive completion and completion intention among citizens of the western Canadian province of Alberta. 7 Palliat Care 2013;29:5-12.

Affiliations: Department of Neurology (A. Richard), Beth Israel Deaconess Medical Center, Harvard University, Boston, Mass.; independent scholar (J. Richard), Vancouver, BC; Division of Neurology (Johnston, Miyasaki), Faculty of Medicine and Dentistry, University of Alberta, Edmonton, Alta.

Contributors: Alby Richard, Wendy Johnston and Janis Miyasaki conceived the idea for this study. Alby Richard and Joël Richard analyzed the data and drafted the article. All authors revised the article critically, gave final approval of the version to be published and agreed to be accountable for all aspects of the work.

Supplemental information: For reviewer comments and the original submission of this manuscript, please see www.cmajopen.ca/content/6/3/ E406/suppl/DC1 